\title{
A modified Mitscherlich model and its degradation kinetics equations
}

\author{
Fatih Uckardes \\ Department of Biostatistics and Medical Informatics, Medicine Faculty, Adiyaman University, Turkey
}

\begin{abstract}
The aim of this study was to show how to adapt and convert the Mitscherlich model to animal nutrition studies in a theoretical way. The new form of the model was obtained by applying a mathematical conversion step by step to use the Mitscherlich model in an in vitro gas production or in in situ nylon bag studies which have an important role in animal nutrition. The parameter which is not included in new model but important for digestion was gained for the model. Moreover, it was shown how to obtain important digestion equations by using the new form of Mitscherlich model. Also the equation formulas were obtained for both with and without lag-phase. Consequently, it was shown how to convert a model, which is previously not used in terms of animal nutrition, into a different purposive form and how to obtain the new equations from this form step by step in a theoretical way. Besides, the new form of Mitscherlich model, which is an alternative to other models, will importantly contribute to the literature by obtaining some important equations not found in many of the other models.
\end{abstract}

Keywords: Mitscherlich model; in situ; in vitro; mathematical model; effective degradability

Abbreviations: RSS: Residual Sum of Square 


\section{Introduction}

Mathematical models have been used for a long time to predict the kinetics of digestion of forage. Axelsson (1938) reported the first study in this discipline to determine the estimated regression equation of the dry-matter digestion of the forage obtained by the method of in vivo. McMeekan (1943) added standard errors of the regression equation and correlation coefficient to the model. Due to the high standard errors of regression equations in the studies conducted in these years, studies were carried out to reduce the standard error (Kivimäe 1960). However, in later years the demand for mathematical models increased more with the discovery of in vitro and in situ techniques (Tilley et al. 1960, Tilley \& Terry 1963, McLeod \& Minson 1969 and Menke et al. 1979). Today, models which have exponential and sigmoidal structure have been used to better estimate the results of in vitro gas production and in situ digestibility (France et al. 2005, Sahin et al. 2011 and Wang et al. 2011). Furthermore, López et al. (1999), France et al. (2000, 2005), Wang et al. (2011), Sahin et al. (2011) and Uckardes et al. (2013) derived new formulas from the models to better explain the functioning of the system apart from containing forage digestibility parameters which are biologically meaningful. However, López et al. (1999) and France et al. (2000) reported that the new formulas derived from the model sometimes do not give the requested result and thus do not have an analytical solution. The main reason for using a different structure and a large number of models is to predict the kinetics of digestion in the best way. As it can be seen today, there are still many studies looking for the answer to the question how to predict forage digestion kinetics better and more accurately.

The main aim of this study was to show how to adapt and convert the Mitscherlich model, which is used in plant nutrition studies, to animal nutrition studies in a theoretical way. In addition, it was aimed to show how to obtain some parameters which are not included in the model to describe the kinetics of forage digestion better by using the new form of (modified) Mitscherlich model. Thus, it was aimed to gain a new model and new formulas foranimal nutrition.

\section{Methods}

As shown in Figure 1, the degradation or gas production has an exponential curve and three phases. These three phases can be described with three parameters: the maximum gas production or degradation (a), initial gas production or degradation (d) and constant rate (c). We simply show here the modification of the Mitscherlich model to describe these phases. The general equation of the Mitscherlich model is as below (Mitscherlich 1909),

$$
y=a(1-b \exp (-c t))
$$

where $a$ is the asymptotic value, $b$ is the characteristic curve, $c$ is the constant rate and $t$ is the time.

The parameter $b$ in Eq. (1) does not have a biological meaning. This parameter, which defines gas production or degradation, is replaced by another. That means, when $t_{0}=0$, it can be found as an initial value $y_{0}=a(1-b)$. For $d=a(1-b), b=(1-d / a)$. Inserting this result into the Eq. (1) it can be written the following (modified) re-parameterized version:

$$
y=a(1-(a-d)(\exp (-c t)) / a)
$$



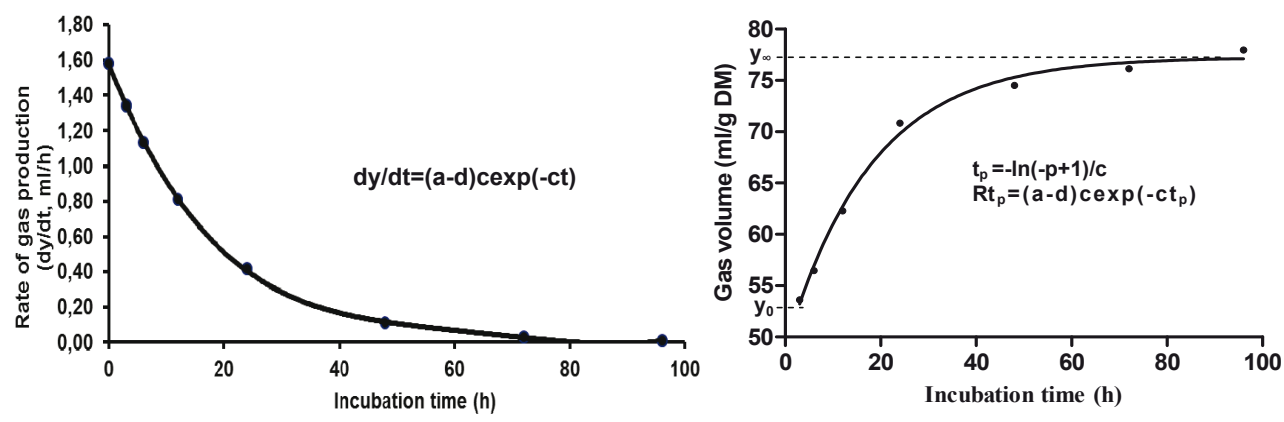

Figure 1

The behaviour of the modified Mitscherlich model on a data produced as hypothetical $y=77.26(1-(77.26-$ 48.84) $(\exp (-0.05574 \mathrm{t})) / 77.26), \mathrm{R} 2=0.9944$

Many studies have discussed the importance of the parameter d (Theodorou et al. 1994, Schofield et al. 1994 and Kamalak et al. 2005). These important parameters have been gained for the Mitscherlich model. Since the number of parameters of the modified Mitscherlich model is saved as a result of the conversion above, the new form and the oldest form of the model have the same characteristic.

The parameter meanings in vitro and in situ of the modified Mitscherlich model are summarized in Table 1.

Table 1

Parameter meanings for in vitro and in situ of the modified Mitscherlich model

\begin{tabular}{lll}
\hline Parameters & In vitro gas production technique & In situ nylon bag technique \\
\hline $\mathrm{a}:$ & the potential gas production $(\mathrm{ml})$ & the potential degradability (\%) \\
$\mathrm{d}:$ & the gas production from the immediately & the rapidly soluble fraction (\%) \\
& fraction $(\mathrm{ml})$ & \\
$\mathrm{a}-\mathrm{d}:$ & the gas production from the insoluble & the potentially degradable fraction (\%) \\
& fraction (ml) & \\
$\mathrm{c}:$ & the gas production rate constant $\left(\mathrm{h}^{-1}\right)$ & the constant rate of degradability $\left(\mathrm{h}^{-1}\right)$ \\
$\mathrm{t}:$ & the incubation time $(\mathrm{h})$ & the degradability time $(\mathrm{h})$ \\
$\mathrm{y}:$ & the gas produced at $\mathrm{t}$ time & the dry matter disappearance in rumen at t time
\end{tabular}

However, Ørskov \& McDonald (1979) reported that they obtained some new equations to access more information about forage digestion by using the models. France et al. (2000) and Sahin et al. (2011) also reported that only the model parameters are not sufficient to predict the kinetics of digestion. It is shown below how to obtain the most important ones of these formulas by using a modified Mitscherlich model.

The digestion kinetics equations can be found as below step by step using Eq. (2).

1. Rate of gas production or degradation: The first derivative of Eq. (2), represented as rate of gas production or degradation, can be expressed as (Figure 1),

$$
d y / d t=(a-d) \operatorname{cexp}(-c t)
$$


and the second derivative of Eq. (3), can be expressed as,

$$
d^{2} y / d t^{2}=-(a-d) c^{2} \exp (-c t)
$$

for each $\mathrm{t},{ }^{\prime} \mathrm{d}^{2} \mathrm{y} / \mathrm{dt}^{2 \prime} \neq 0$, so the Mitscherlich model has no inflection point.

2. The effective degradability: Orskov \& McDonald (1979) derived a method to estimate the effective degradabilities of protein. This method can also be used to estimate some important materials such as Dry Matter (DM) and Neutral Detergent Fibre (NDF) (López et al. 1999 and Ghorbani \& Hadj-Hussaini 2002). This method is applied in the modified Mitscherlich model as below.

Where the cumulative percentage protein degradation up to time $\mathrm{t}$ can be obtained by integration

$$
\begin{aligned}
y t & =\int_{0}^{t} f \frac{d y}{d t} d t \\
& =\int_{0}^{\mathrm{t}} \exp (-k t)(a-d) c \exp ^{(-c t)} d t \\
y t & =(a-d) c(\exp (-t(k+c))-1) /(k+c)
\end{aligned}
$$

Where $f$ represents the fraction of the treated protein which still remains in the rumen at $\mathrm{t}$ hours after feeding then $\mathrm{f}=\exp (-\mathrm{kt})$. The water soluble proteins must be added to the Eq. (5) which are known to degrade very rapidly. Thus,

$$
y t=d+(a-d) c(\exp (-t(k+c))-1) /(k+c)
$$

Where for ' $t=\infty$ ' The percentage protein approaches closer and closer to the final value

$$
y=d+(a-d) c /(k+c)
$$

Where: $\mathrm{k}$ is a fractional rate.

3. The partial fermentation or degradation times $\left(t_{p}\right)$ : They can be calculated using the equation below (Fig 1).

$$
y_{0}+\left(y_{\infty}-y_{0}\right) p / 100=y\left(t_{p}\right)
$$

Where the values of $y_{0}$ and $y_{\infty}$ are $d$ and $a$, respectively. $t_{p}$ is time (h) to produce $\mathrm{p} \%$ of total fermentation or degradation, $y(t p)$ is disappearance at time tp. If the modified Mitscherlich model is rewritten using Eq. (8), the following equation is obtained:

$$
d+(a-d) p / 100=a\left(1-(a-d)\left(\exp -\left(c t_{p}\right)\right) / a\right)
$$

By solving the Eq. (9) a general equation of $t_{p}$ is obtained as below.

$$
t_{p}=-\ln (-p+1) / c
$$

Where: $p$ may have any value in the range 0-100 using a percentage scale.

4. The rate of the partial fermentation or degradation at the time $t p(R t p)$ : The general equation of Rtp can be found by taking the first derivative of the Eq. (2). So, the general equation of Rtp can be expressed as;

$$
R t_{p}=d y / d t_{p}=(a-d) \operatorname{cexp}\left(-c t_{p}\right)
$$

5. By-pass protein: It can be calculated using Eq. (7) as below. 
By-pass protein $(\%)=100-d+(a-d) c /(k+c)$

The similar procedures were performed in the modified Mitscherlich model with a lag phase. These results are given in Table 2.

In this study, the Maple program was used for mathematical procedures (Maple 2001).

Table 2

The properties equation of the modified Mitscherlich model with normal and lag phase

\begin{tabular}{lll}
\hline Property & Normal phase & Lag phase \\
\hline $\begin{array}{l}\text { Normal equation } \\
\text { Modified equation }\end{array}$ & $\mathrm{y}=\mathrm{a}(1-\mathrm{bexp}(-\mathrm{ct}))$ & $\mathrm{y}=\mathrm{a}(1-\mathrm{bexp}(-\mathrm{c}(\mathrm{t}-\mathrm{\lambda})))$ \\
$\begin{array}{l}\text { Rate of fermentation } \\
\text { or degradation }\end{array}$ & $\mathrm{y}=\mathrm{a}(1-(\mathrm{a}-\mathrm{d})(\exp (-\mathrm{ct})) / \mathrm{a})$ & $\mathrm{y}=\mathrm{a}(1-((1 / \mathrm{m}-\mathrm{d} /(\mathrm{ma})) \exp (-\mathrm{c}(\mathrm{t}-\lambda)))$ \\
$\begin{array}{l}\text { Inflection point } \\
\text { The effective }\end{array}$ & $(\mathrm{a}-\mathrm{d}) \mathrm{cexp}(-\mathrm{ct})$ & $(\mathrm{a}-\mathrm{d}) \mathrm{cexp}(-\mathrm{c}(\mathrm{t}-\lambda))$ \\
$\begin{array}{l}\text { degradability (\%) } \\
\text { tp (h) }\end{array}$ & - \\
$\begin{array}{l}\text { Rtp (h-1) } \\
\text { By pass protein (\%) }\end{array}$ & $\mathrm{d}+(\mathrm{a}-\mathrm{d}) \mathrm{c} /(\mathrm{k}+\mathrm{c})$ & $\mathrm{d}+(\mathrm{a}-\mathrm{d}) \mathrm{c} /(\mathrm{k}+\mathrm{c})$ \\
\hline
\end{tabular}

$\mathrm{k}$ : fractional rate, $\mathrm{m}=\exp (\mathrm{c} \lambda), \lambda$ : Lag time

\section{Results}

The means of parameters by the modified Mitscherlich model for in vitro and in situ degradation techniques are given in Table 1. As it can be seen, 'd' is a new biological meaningful parameter. In addition, the various mathematical equations describing in vitro gas production and in situ nylon bag using the modified Mitscherlich are presented in Table 2 .

\section{Discussion}

A mathematical model can be modified in two different ways. Firstly, the parameter which has no biological meaning can be replaced with another parameter with biological meaning. The Mitscherlich model used in many studies in plant growth and nutrition (Mitscherlich 1909 and Harmsen 2000) was applied to a similar approach in this study. Consequently, the number of the parameters of the modified model did not change and therefore the characteristic of the model was saved. Similarly, Zwietering et al. (1990) reported that they modified the Logistic, Gompertz, Richards, Stannard and Schunute models, which have sigmoidal structure, in a similar way to more define the bacterial growth.

Secondly, a model can be modified by either increasing or decreasing the number of parameters. Schofield et al. (1994) applied some modifications to the Logistic and Gompertz models and added a new parameter. In a similar manner, Wang et al. (2011) decreased the Residual Sum of Square (RSS) value of model adding the shape parameter »d « to the Logistic model for better definition of in vitro gas production kinetics and thus they tried to make the model more flexible. At the end of these studies, structure of the modified model changed by increasing the number of parameters compared to the previous model. 
Zwietering et al. (1990) underlined that an increase in the number of parameters during the modification process of a model will probably reduce RSS, but adversely lower the chance of selection of the model. For this reason, in this study the parameter ' $b$ ' providing shape of the curve was replaced by the parameter ' $d$ ' by applying a kind of transformation instead of introducing an additional parameter in the Mitscherlich model. In this way, the structure of the model and the number of parameters were kept constant.

Motulsky \& Ransnas (1987) and Zwietering et al. (1990) emphasized that the model with less parameters rather than the model with more parameters should be preferred since it is easier to fit the model with less parameters and the parameters are less correlated. Additionally, López et al. (1999) and Korkmaz et al. (2011) reported that Akaike Information Criteria, Bayesian Information Criteria and F ratio test prefer the model with a smaller number of parameters while selecting the model.

France et al. (1993) proposed a Generalized Michaelis-Menten model by introducing a modified fractional degradation rate with time in the exponential model. They believed that sigmoidal shapes reflected increased substrate accessibility, which might be caused by increased hydration of particles, microbial attachment and microbial numbers at the beginning of incubation. France et al. (2000) investigated sigmoidal and non-sigmoidal structures of some important models. They examined sigmoidal and non-sigmoidal structures of the models such as generalization of Mitscherlich and generalized MitscherlichMenten, according to whether the parameter $c$ which generates the shape of the curve, is greater or less than 1. In conclusion, these models have either sigmoidal (c $\square$ 1) or nonsigmoidal shapes (c>1). Generally, the models with an exponential phase indicate that the rate of gas production or the rate of degradability decreases continually, while the sigmoidal shape indicate that rate of gas production or the rate of degradability increases firstly, reaches the maximum rate and then decreases, which might be suggested a close relationship with increased microbial activities during the early stages of incubation (Wang et al. 2011).

Various equations may be obtained by using mathematical models. Firstly, the most important equation is the effective digestibility suggested by Orskov \& McDonald (1979). Many researchers also employed the Orskov model to calculate the effective digestibility (Ghorbani \& Hadj-Hussaini 2002; Kamalak et al. 2005 and Sallam et al. 2007). A similar approach is applied to the modified Mitscherlich model in this study. The results are given in Table 2. In this study, it was very easy to calculate the effective degradability in the modified Mitscherlich model similar to the Orskov Model. However, López et al. (1999) and France et al. (2000) suggested some models such as Generalized Mitscherlich, Generalized Mitscherlich - Menten, Gompertz and Logistic with the same approach. But they could not find any analytical solution of the integral equations and expressed that these models should be evaluated numerically.

Secondly, the time (tp) to produce $\mathrm{p} \%$ of total fermentation or degradation is a very important parameter for the comparison of the feedstuffs by using in vitro gas production or in situ degradability (France et al. 1993, 2000, López et al. 1999, Sahin et al. 2011 and Uckardes et al. 2013). France et al. (1993) first proposed the tp equation. This equation was used by many subsequent studies (Theodorou et al. 1994, López et al. 1999, Kamalak et al. 2005 and Tedeschi et al. 2008). 
France et al. (2000) have given the equations related to tp values for some sigmoidal models such as Gompertz, Logistic, generalized Michaelis-Menten and generalization of Mitscherlich model. Although Sahin et al. (2011) obtained many general equations for the exponential model, t25 t50 t75 and t95, they have not given a general equation and any tp times for a model with lag phase. Wang et al. (2011) modified the Logistic model in order to better define in vitro gas production kinetics and included only the equation for time of $\mathrm{t} 50$. In this study, the general tp equations with normal and lag phase of the modified Mitscherlich model are given in Table 2. The tp value can be calculated for the required time period in Table 2. Moreover, the rate of the partial fermentation or degradation at the time tp (Rtp) can be calculated by using the modified Mitscherlich model.

Two different phases of the modified Mitscherlich model and their formulas are given in Table 2. The modified Mitscherlich model can be used to fit in situ degradation and in vitro gas production data. While the modified Mitscherlich model with a normal phase can be more suitable for feedstuffs, the model with a lag phase can be more suitable for roughages in estimating in situ digestion kinetics. In addition, the modified Mitscherlich model with a lag phase can also be used to estimate in vitro fermentation kinetics of feedstuffs or roughages due to a little or no gas production in the early stage of fermentation (Sahin et al. 2011). On the other hand, if the lag time has a very small value, use of the model with the lag phase are not required (France et al. 2000).

In conclusion, the Mitscherlich model was modified by adding a new biological meaningful parameter to describe the degradation kinetics. In addition to the »c«, »d« and »a« used in the modified Mitscherlich model, the estimation of »the effective degradability«, »tp«, »Rtp« and »By pass protein« may provide more useful data to compare feedstuffs and roughages in terms of in vitro fermentation and in situ degradation studies. The study presented new theoretical approaches to the Mitscherlich model regarding the description of in situ nylon bag and in vitro gas production techniques.

More comprehensive studies which use longer incubation and degradation times, more incubation points, different gas measurement systems and wider ranges of feedstuffs or roughages are needed to completely investigate the performance of the modified Mitscherlich model since this study was done in a theoretical way.

Moreover, it is a contribution to the researchers in this discipline that the modified Mitscherlich model represent an alternative to other models, it is also shown how to derive equations from the model step by step.

\section{Acknowledgements}

The author thanks to Dr. Erdal Unluyol for his helpful criticism on this manuscript and to Elif Aslan.

\section{References}

Axelsson J (1939) [The stimulatory effect of the protein in animal feed]. Tierernahrung 11, 162-175 [in German] France J, Dhanoa MS, Theodorou MK, Lister SJ, Davies DR, Isac D (1993) A Model to Interpret Gas Accumulation Profiles Associated with In vitro Degradation of Ruminant Feeds. J Theor Biol 163, 99-111 
France J, Dijkstra J, Dhanoa MS, Lopez S, Bannink A (2000) Estimating the extent of degradation of ruminant feeds from a description of their gas production profiles observed in vitro: derivation of models and other mathematical considerations. Br J Nutr 83, 143-150

France J, Lopez S, Kebreab E, Bannink A, Dhanoa MS, Dijkstra J (2005) A general compartmental model for interpreting gas production profiles. Anim Feed Sci Technol 123-124, 473-485

Goharbani GR, Hadj-Hussaini A (2002) In situ degradability of Iranian barley grain cultivars. Small Rumin Res $44,207-212$

Harmsen K (2000) A modified Mitscherlich equation for rainfed crop production in semi-arid areas. 1. Theory. Neth J Agric Sci 48, 237-250

Kamalak A, Canbolat O, Gurbuz Y, Erol A, Ozay O (2005) Effect of maturity stage on chemical composition, in vitro and in situ dry matter degradation of tumbleweed hay (Gundelia tournefortii L.). Small Rumin Res 58, 149-156

Kivimäe A (1960) Estimation of the digestibility of grassland crops from their chemical composition. In: Proc 8th Int Grassld Congr, 466-470

Korkmaz M, Üçkardeş F, Kaygisiz A (2011). Comparison of wood, gaines, parabolic, hayashi, dhanno, and polynomial, models for lactation season curve of Simmental cows. J Anim Plant Sci 21, 448-458

López S, France J, Dhanoa MS, Mould F, Dijkstra J (1999) Comparison of mathematical models to describe disappearance curves obtained using the polyester bag technique for incubating feeds in the rumen. $J$ Anim Sci 77, 1875-1888

Maple (2001) Maple version 6.02. Waterloo Maple Inc., Waterloo, Ontario, Canada

McLeod MN, Minson DJ (1969) Sources of variation in the in vitro digestibility of tropical grasses. Grass Forage Sci 24, 244-249

McMeekan CP (1943) A note on the relationship between crude fibre and digestibility of organic matter. N Z J Sci Technol A 25, 152-153

Menke KH, Raab L, Salewski A, Steingass H, Fritz D, Schneider W (1979) The estimation of the digestibility and metabolizable energy content of ruminant feedingstuffs from the gas production when they are incubated with rumen liquor in vitro. J Agric Sci (Cambridge) 93, 217-222

Mitscherlich EA (1909) [The law of the minimum and the law of diminishing soil productivity]. Landw Jahrb 38, 537-552 [in German]

Motulsky HJ, Ransnas LA (1987) Fitting curves to data using nonlinear regression: a practical and nonmathematical review. FASEB J 1, 365-374

Ørskov ER, McDonald I (1979) The estimation of protein degradability in the rumen from incubation measurements weighted according to rate of passage. J Agric Sci (Cambridge) 92, 499-503

Sallam SMA, Nasser MEA, EL-Waziry AM, Bueno ICS, Abdalla AL (2007) Use of an in vitro Rumen Gas Production Technique to Evaluate Some Ruminant Feedstuffs. J Appl Sci Res 3, 34-41

Schofield P, Pitt RE, Pell, AN (1994) Kinetics of fiber digestion from in vitro gas production. J Anim Sci 72, 2980-2991

Sahin M, Uckardes F, Canbolat O, Kamalak A, Atalay Al (2011) Estimation of Partial Gas Production Times of Some Feedstuffs Used in Ruminant Nutrition. Kafkas Univ Vet Fak Derg 17, 731-734

Tedeschi LO, Schofield P, Pell AN (2008) Determining feed quality for ruminants using in vitro gas production technique. 1. Building an anaerobic fermentation chamber. In: The 4th Workshop on Modeling in Ruminant Nutrition: Application of the Gas Production Technique, Juiz de Fora, Brazil

Theodorou MK, Williams BA, Dhanoa MS, McAllan AB, France J (1994) A simple gas production method using a pressure transducer to determine the fermentation kinetics of ruminant feeds. Anim Feed Sci Technol 48, 185-197

Tilley JMA, Deriaz RE, Terry RA (1960) The in vitro measurement of herbage digestibility and assessment of nutritive value. In: Proc 8th Int Grassld Congr, 533-537

Tilley JMA, Terry RA (1963) A two-stage technique for the in vitro digestion of forage crops. Grass Forage Sci $18,104-111$ 
Uckardes F, Korkmaz M, Ocal P (2013) Comparison of models and estimation of missing parameters of some mathematical models related to in situ dry matter degradation. J Anim Plant Sci 23, 999-1007

Wang M, Tang SX, Tan ZL (2011) Modeling in vitro gas production kinetics: Derivation of Logistic-Exponential (LE) equations and comparison of models. Anim Feed Sci Technol 165, 137-150

Zwietering MH, Jongenburger I, Rombouts FM, Van't Riet K (1990) Modeling of the Bacterial Growth Curve. Appl Environ Microbiol 56, 1875-1881 